\title{
A NeW SPECIES IN THE RHEOCRICOTOPUS (R.) EFFUSUS GROUP FROM CANADA WITH A REVIEW OF THE NEARCTIC SPECIES OF RHEOCRICOTOPUS AND Parametriocnemus (Chironomidae: Orthocladinae)
}

\author{
Armin Namayandeh ${ }^{1}$ and David V. Beresford ${ }^{2}$ \\ ${ }^{1}$ Taxanama Corp., 25 Mabelle Ave, Toronto, ON, M9A 4Y1, Canada. \\ E-mail: a.namayan@taxanama.com \\ ${ }^{2}$ Department of Biology, Trent University, Peterborough, Ontario, Canada. \\ E-mail: davidberesford@,trentu.ca
}

http://zoobank.org/urn:lsid:zoobank.org:pub:3625C1D8-40F1-44D9-8571-97C481739253

\begin{abstract}
Rheocricotopus (Rheocricotopus) reduncusoides sp. n. is described from Bathurst Island, Nunavut, Canada. Its discovery was made while curating and examining specimens deposited by H. V. Danks in 1969 at the Canadian National Collection in Ottawa, Canada. We also report the first Canadian record of Parametriocnemus hamatus (Johannsen, 1934) from Québec, based on previously unsorted material deposited at the Canadian National Collection. In this paper we provide distributional records of the Nearctic species of Rheocricotopus Thienemann and Harnisch and Parametriocnemus Goetghebuer, and present a key to the Nearctic adult males of these genera.
\end{abstract}

\section{Introduction}

While curating mounted specimens of Chironomidae at the Canadian National Collection of Insects, Arachnids and Nematodes (CNC), we encountered six specimens that had been placed into the wrong genus. Five of these were adult males from materials previously collected during 1969 Arctic expedition by H.V. Danks and J. R. Byers to Bathurst Island, Nunavut, Canada (Danks and Byers 1972). The Chironomidae from this survey were deposited at $\mathrm{CNC}$ for further identification. The original examination of the Bathurst Island material (Danks and Byers 1972) identified 30 species (21 Orthocladiinae) across 18 genera. Overall close to 10,000 Chironomidae specimens were collected (Danks and Byers 1972).

Subsequent publications and descriptions were produced from this expedition (Danks 1971, 1980, 1981, Danks and Oliver 1972a, 1972b, Oliver and Danks 1972, personal communication with Dr. H. V. Danks). In spite of this prodigious publishing output that arose from the 1969 Arctic Expedition, specimens remained that required further investigation.
In this paper we describe Rheocricotopus (Rheocricotopus) reduncusoides $\mathrm{sp}$. n. a new species in Rheocricotopus (R.) effusus group from Nunavut, Canada based on five of these mounted specimens. We also report on a single mounted specimen of Parametricnemus hamatus (Johannsen, 1934) collected by D.R. Oliver in Quebec, 1968. Because there are no geographic coordinates associated with this latter specimen (i.e. only province of Quebec is on the label) the exact locality of the collection remains unknown. Nevertheless, this is a new geographic record for Canada. Parametricnemus hamatus is only reported in eastern and southeastern USA. In this study we provided additional morphological information for Chironomidae species, a list of species from the collection, and a key to adult male for the Nearctic.

\section{Study area and Methods}

In the original field study (Danks and Byers 1972) arthropods were collected within a radius of 4.8 $\mathrm{km}$ of a campsite at $75^{\circ} 43^{\prime} 00^{\prime}$ N, $98^{\circ} 25^{\prime} 00^{\prime}$ 'W. The site was located about halfway between the paired inlets of the west and east coast which characterize south-central Bathurst Island. Dry ridges and their upper slopes formed rather typical Saxifraga barrens. South of the ridges there was an extensive sedge marsh with numerous shallow ponds and two shallow lakes. The northern part of marsh is adjacent to the Goodsir River which runs southwards before turning eastwards towards Goodsir Inlet (Danks and Byers 1972).

Pan traps were used to collect arthropods both on ridges and in the marsh. Additionally, drift nets were used in several creeks. Further sampling was conducted by searching amongst vegetation, beneath stones, and around carrion by sweeping, especially in the marsh habitat (Danks and Byers 1972). There are no associated reports for the collection of $P$. hamatus in Quebec. 
Geographical records are based on Ashe and O'Connor (2012) with additional records mined from the Barcode of Life Data Systems (BOLD Systems), Namayandeh (2016), Namayandeh and Culp (2016) and Namayandeh et al (2012, 2016). We made type specimens of the mounted materials along with new identification labels and returned all the loaned specimens to the CNC. Images were obtained by OMAX A3550U Camera mounted on AMScope compound scope.

In this paper, we use the terminology and abbreviations as defined by Sæther (1980).

\section{Parametriocnemus and Rheocricotopus species recorded in North America}

Parametriocnemus Goetghebuer consist of 35 named and described species worldwide (Ashe and O'Connor 2012). There are at least seven provisional species that have no formal names, six occurring in the Neotropical region and one in the Oriental region (Ashe and O'Connor 2012). The highest diversity of the genus is in the Palearctic with 21 species with three new records from Palaearctic China including $P$. lundbeckii. Palearctic is a relatively well-studied region and therefore, this high diversity of the species is to be expected. The more northern parts of the Nearctic (NE) are relatively understudied region with only four species listed in the catalogue (Ashe and O'Connor 2012) and one added in this study. Given the cold-stenothermic nature of most Parametriocnemus species, finding a new species and/or new geographic records in the northern Nearctic is likely.

Rheocricotopus Thienemann and Harnisch, in comparison, is a diverse and well-studied genus with 72 named species worldwide (Ashe and O’Connor 2012, Moubayed-Breil 2016). So far 44 species have been described or reported from the Palearctic (Ashe and O'Connor 2012, Krasheninnikov and Loskutova 2015, Liu et al. 2014a, b, Moubayed-Breil 2016, Yamamoto and Yamamoto 2017) and 13 from the Nearctic, including the present study. Published records of Rheocricotopus species from the Holarctic indicates seven species occur in both the Nearctic and Palearctic regions with more expected overlapping. This is especially true for those species from Far East Russia (Makarchenko and Makarchenko 2005). However, extent of this overlapping needs a detailed investigation. Recent records (BOLD Systems) have revealed that Rheocricotopus (Psilocricotopus) chalybeatus (Edwards 1929), previously only known from the Palearctic also occur in the Nearctic. Furthermore, the occurrence of several species in both the eastern and western Nearctic (BOLD Sys- tems, Namayandeh 2016, Namayandeh et al. 2016, Namayandeh and Culp 2016) suggest that many species likely have a widespread distribution.

\section{Parametriocnemus Goetghebuer}

\section{Parametriocnemus boreoalpinus Gowin and Thienemann, 1942}

Adults: Male and female described by Gowin and Thienemann (1942).

Immatures: Pupa and larva Gowin and Thienemann (1942) and Kownacka and Kownacki (1967).

Ecology and Habitat: Larvae inhabit the stony banks of high-altitude streams (Kownacka and Kownacki 1967).

NE: Canada (Alberta, British Columbia, Labrador, Northwest Territories, Nunavut). Widespread in the Palearctic.

\section{Parametriocnemus eoclivus Sæther, 1969}

Adults: Male and female described by Sæther (1969).

Immatures: Pupa and larva described by Sæther (1969).

Ecology and Habitat: Larvae inhabit lotic habitats (Sæther 1969).

NE: Canada (Québec); USA (North Carolina, Tennessee). In Palearctic, only recorded in Italy (dubious record).

\section{Parametriocnemus graminicola (Lundbeck, 1898)}

Adults: Male described by Sæther (1969) and Sublette (1966). Female is unknown.

Immatures: Unknown.

Ecology and Habitat: Adults collected near lentic habitats (Sæther 1969).

NE: Canada (Alberta, Northwest Territories, Yukon Territory); Greenland. In the Palearctic, recorded only in Far East Russia.

\section{Parametriocnemus hamatus (Johannsen, 1934)}

Adults: Male described by Sublette (1967) as Paraphaenocladius hamatus (Johannsen 1934). Female is unknown.

Immatures: Unknown. Apparently, the larva of this species was reared by M. J. Bolton. However, no records of larval description are available.

Ecology and Habitat: Adults collected near springs and runs of Cedar Bog, an alkaline fen in Ohio, USA (Bolton 1992). 
NE: Canada, first record (Québec); USA (Connecticut, Florida, Maine, New York, North Carolina, Ohio).

\section{Parametriocnemus lundbeckii (Johannsen, 1905)}

Adults: A detailed description of adults are given by Sæther (1969) and Sublette (1967).

Immatures: Pupa and larva described by Sæther (1969), and Namayandeh and Culp (2016). Larva described by Namayandeh et al. (2012), and Simpson and Bode (1980).

Ecology and Habitat: Larvae inhabit clean piedmont and mountain streams (McShaffrey and Olive 1985, Simpson and Bode 1980).

NE: Canada (Alberta, Northwest Territories, Ontario, Québec, Saskatchewan); USA (Alabama, Arizona, California, Florida, Georgia, Michigan, New Mexico, New York, North Carolina, Ohio, South Carolina, Texas). In the Palearctic, records were made by E. Stur and T. Ekrem (2010) in Norway as part of Barcode of Life, Centre for Biodiversity Genomics (Ratnasingham and Hebert 2007). Also, recently this species was reported from China by Li et al. (2013).

\section{Parametriocnemus vespertinus Sæther, 1969}

Adults: Male described by Sæther (1969). Female unknown.

Immatures: Pupa described by Sæther (1969). Larva unknown.

Ecology and Habitat: Larvae likely inhabit lotic habitats (Sæther 1969).

NE: Canada (Alberta).

\section{Rheocricotopus Thienemann and Harnisch}

atripes group:

Rheocricotopus (Psilocricotopus) glabricollis (Meigen, 1830)

Adults: Male described by Lehman (1969), Sæther (1985), Makarchenko and Makarchenko (2005), hypopygium in key by Pinder (1978). Female described by Sæther (1985).

Immatures: Pupa described by Sæther (1985), figs. in Lehman (1969) under R. gouini, and in key by Langton (1991). Larva described in Namayandeh (2016), and in key by Epler (2001).

Ecology and Habitat: Larvae inhabit lotic habitats (Hudson et al. 1990).

NE: Canada (Manitoba, New Brunswick); USA (Georgia, North Carolina, Ohio, Pennsylvania,
South Carolina, Tennessee). Widespread in the Palearctic.

chalybeatus group:

\section{Rheocricotopus (Psilocricotopus) chalybeatus (Edwards, 1929)}

Adults: Male described by Lehman (1969), Sæther (1985), hypopygium in key by Pinder (1978). Female described by Sæther (1985).

Immatures: Pupa described by Sæther (1985), in key by Langton (1991), figures in Lehman (1969). Larva by Cranston (1982).

Ecology and Habitat: Larvae inhabit springs and streams (Cranston 1982, Lehman 1971).

NE: Canada (Nunavut). Widespread in the Palearctic.

Rheocricotopus (Psilocricotopus) chapmani (Edwards, 1935)

Adults: Male and female described by Sæther (1985).

Immatures: Unknown.

Ecology and Habitat: Adults collected near lentic and lotic habitats (Sæther 1985).

NE: Canada (Northwest Territories, Nunavut, Yukon Territory); Greenland. In the Palearctic, recorded in Finland and Norway.

\section{Rheocricotopus (Psilocricotopus) robacki (Beck and Beck, 1964)}

Adults: Male described by (Beck and Beck 1964) as Trichocladius robacki and by Sæther (1969) as R. kenorensis. Female described by Sæther (1985).

Immatures: Pupa and larva described by Sæther (1985). Larva in key by Epler (2001).

Ecology and Habitat: Fast flowing streams (Sæther 1969).

NE: Canada (Alberta, British Columbia, Ontario, Saskatchewan, Yukon Territory); USA (Alabama, Arizona, California, Florida, Georgia, Mississippi, Montana, New York, North Carolina, Ohio, Pennsylvania, South Carolina, South Dakota, Tennessee). Recently reported from the Palaearctic China (Xinjiang Uyghur Auto. Region) by Liu et al. (2014a).

effusus group:

Rheocricotopus (Rheocricotopus) effusoides Sæther, 1985

Adults: Male and female described by Sæther (1985). 
Immatures: Pupa and larva described by Sæther (1985).

Ecology and Habitat: Larvae inhabit lotic habitats (Sæther 1985).

NE: USA (Ohio, South Dakota).

Rheocricotopus (Rheocricotopus) effusus (Walker, 1856)

Adults: Male described by Albu (1968), Lehman (1969), Sæther (1985), Makarchenko and Makarchenko (2005), hypopygium in key by Pinder (1978). Female described by Sæther (1985).

Immatures: Pupa described by Sæther (1985), in key by Langton (1991). Larva described by Cranston (1982), Sæther (1985), and in key by Epler (2001).

Ecology and Habitat: Larvae mainly inhabit springs (Thienemann 1954).

NE: Canada (Alberta, Northwest Territories); USA (Illinois, North Carolina, South Carolina, South Dakota). Widespread in the Palearctic.

\section{Rheocricotopus (Rheocricotopus) pauciseta Sæther, 1969}

Adults: Male described by Sæther (1969), and Makarchenko and Makarchenko (2005). Female is unknown.

Immatures: Pupa and larva described by Sæther (1969) and in key by Epler (2001).

Ecology and Habitat: Lotic habitats (Hudson et al. 1990).

NE: Canada (Alberta, British Columbia, Labrador); USA (North Carolina). In the Palearctic Far East Russia, recently from China (Sichuan Province), Tibet by Liu et al. (2014b).

\section{Rheocricotopus (Rheocricotopus) reduncusoides} sp. $n$.

Adults: Male described in this study. Female is unknown.

Immatures: Unknown.

Ecology and Habitat: Specimens were collected probably near creeks close to the marshland in $\mathrm{Ba}-$ thurst Island (Danks and Byers 1972).

NE: Canada (Nunavut).

Rheocricotopus (Rheocricotopus) unidentatus Sather and Schnell, 1988

Adults: Male and female described by Sæther and Schnell (1988).

Immatures: Pupae and larva described by Sæther and Schnell (1988). Larva in key by Epler (2001) and described by Namayandeh et al. (2012).

Ecology and Habitat: Larvae inhabit streams and springs (Sæther and Schnell 1988). Namayandeh et al. (2012) collected the larvae from leaf litter in headwater streams located on the Precambrian Shield.

NE: Canada (Ontario); USA (North Carolina, Ohio).

\section{fuscipes group:}

Rheocricotopus (Rheocricotopus) amplicristatus Sæther, 1985

Adults: Male and female described by Sæther (1985).

Immatures: Unknown.

Ecology and Habitat: Adults collected near creeks (Sæther 1985).

NE: USA (Georgia, South Carolina).

\section{Rheocricotopus (Rheocricotopus) eminellobus Sæther, 1969}

Adults: Male described by Sæther (1969), and Makarchenko and Makarchenko (2005). Female described by Sæther (1969).

Immatures: Pupa described by Sæther (1969). Larva described by Sæther (1985), in key by Epler (2001), and Namayandeh et al. (2012, 2016).

Ecology and Habitat: Larvae are shredders and inhabit leaf litter in running waters (Namayandeh et al. 2012).

NE: Canada (Alberta, Labrador, Ontario); USA (North Carolina, Ohio, South Carolina, Tennessee). In the Palearctic, found only in the Far East Russia.

godavarius group:

\section{Rheocricotopus (Psilocricotopus) conflusirus Sather, 1985}

Adults: Male described by Sæther (1985). Female is unknown.

Immatures: Unknown.

Ecology and Habitat: Adults collected near reservoirs (Sæther 1985).

NE: USA (South Carolina).

tuberculatus group:

Rheocricotopus (Rheocricotopus) tuberculatus Caldwell, 1984

Adults: Male and female described by Caldwell (1984) and Sæther (1985). 
Immatures: Pupae described by Caldwell (1984) and Sæther (1985). Larva by Caldwell (1984), Namayandeh et al. (2012), and in key by Epler (2001).

Ecology and Habitat: In Georgia and North Carolina larvae occurred in second and third order piedmont streams feeding on detritus and diatoms (Caldwell, 1984). Namayandeh et al. (2012) collected the larvae from leaf litter in headwater streams located on the Precambrian Shield.

NE: Canada (Ontario); USA (Florida, Georgia, North Carolina, South Carolina, Tennessee).

\section{Descriptions}

Parametriocnemus hamatus (Johannsen, 1934)

(Figs 1a-e)

Material examined. Parametriocnemus ( $\left.\begin{array}{ll}1 & \jmath\end{array}\right)$, Old Man Joe Mt. (No such location was found in Québec), Québec, 26 April 1968, Collected by D. R. Oliver, No. CH 767

Diagnostic characters. Virga with $2-3$ long narrow branches. AnP with inflated basal $1 / 2$ to $2 / 3$ with 4 stout setae on each side. IVo narrow and apically hooked. Gc with large projecting CD.

Male $(\mathrm{n}=1)$. Total length $=3.2 \mathrm{~mm}$

Coloration of slide-mounted specimen: Male head and thorax light brown, abdomen golden-brown, halter hyaline to slightly golden, and wing goldenbrown.

Head. Antenna (Fig. 1a), with 13 flagellomeres, ultimate flagellomere $(\mathrm{L}=606 \mu \mathrm{m})$ with apical setae $(\mathrm{L}=35 \mu \mathrm{m}) ; \mathrm{AR}=1.3$. Eyes bare, with parallelsided dorsomedial extension (Fig. 1b). Tentorium $\mathrm{L}=147 \mu \mathrm{m}$ (Fig. 1b). Four coronal setae, six orbitals in single row on each side, Clypeus squared ( $\mathrm{L}=64 \mu \mathrm{m}, \mathrm{W}=68 \mu \mathrm{m})$, bearing nine setae. Palpomeres $\mathrm{p}_{1-5}$, lengths $(\mu \mathrm{m}): 36,42,141,143,207$; $\mathrm{p}_{3}$ with 2 sensilla chaetica.

Thorax. As in Fig. 1c. Antropronotals 11, uniserial; prealars 6 , uniserial. Scutum with six setae in single row.

Wing. Wing with fine punctation and hairs covering most of membrane (Fig. 1d). $\mathrm{L}=2.1 \mathrm{~mm}, \mathrm{~W}=$
$0.6 \mathrm{~mm}$. R with 24 setae, $\mathrm{R}_{1}$ with $15, \mathrm{R}_{4+5}$ with 60 setae. Costa extends pass $R_{4+5}$. $R_{4+5}$ distal to $M_{3+4}$. $\mathrm{Cu}$ curved.

Legs. Fore legs with two spurs ( $\mathrm{Ls}=42 \mu \mathrm{m}, 30$ $\mu \mathrm{m})$, mid tibia with two spurs (Ls=34 $\mu \mathrm{m}, 24 \mu \mathrm{m})$ and hind tibia with 2 spurs $(\mathrm{Ls}=59 \mu \mathrm{m}, 19 \mu \mathrm{m})$ and comb with 12-13 stout setae. Pseudospurs are absent. Mid and hind femurs with keel. Pulvilli reduced. Lengths and proportions of legs in Table 1.

Hypopygium. As in Fig. 1e. Segment IX bilobed. Virga present with 2-3 long narrow branches. Anal point $\mathrm{L}=61 \mu \mathrm{m}$. Superior volsella tapered. Inferior volsella narrow and apically hooked-shaped. Gonocoxite longer than wide $(\mathrm{L}=203 \mu \mathrm{m}, \mathrm{W}=$ $85 \mu \mathrm{m})$ with cluster of long setae medially just below the inferior volsella. Gonostyle more or less rectangular; crista dorsalis large triangular-shaped and strongly projecting above dorsal margin; megaseta $\mathrm{L}=13 \mu \mathrm{m}$. $\mathrm{HR}=3.8, \mathrm{HV}=2.4$.

Remarks. The species was first described by Johannsen, 1934 as Metriocnemus hamatus and indicated its close relationship with Meteriocnemus lundbecki Johannsen differing from the latter only in coloration and hypopygium. Sublette (1967) re-described the species as Paraphaenocladius hamatus (Joh.) with illustration of the male hypopygium.

\section{Key to the known Nearctic adult male Parame-} triocnemus Goetghebuer

Abbreviations: $\mathrm{AnP}=$ Anal Point; $\mathrm{CD}=$ Crista Dorsalis; Gc = Gonocoxite; Gs = Gonostyle; IVo $=$ Inferior Volsella; SVo $=$ Superior Volsella; $\mathrm{T}=$ Tergite.

1a. TIX with AnP short not reaching the IVo (Sæther 1969, fig.62)...P. gramnicola (Lundbeck)

1b. TIX with AnP longer, reaching the IVo..........2

2a. IVo narrow, finger-like with hooked apex (Fig. 1e; Sublette 1967, fig. 35).....

P. hamatus (Johannsen)

2b. IVo with broad base and rounded apex.............3

3a. AnP very long reaching beyond IVo; CD en-

Table 1. Male leg lengths $(\mu \mathrm{m})$ and proportions of Parametriocnemus hamatus.

\begin{tabular}{cccccccccccc}
\hline & $\mathbf{f e}$ & $\mathbf{t i}$ & $\mathbf{t a}_{\mathbf{1}}$ & $\mathbf{t a}_{\mathbf{2}}$ & $\mathbf{t a}_{\mathbf{3}}$ & $\mathbf{t a}_{\mathbf{4}}$ & $\mathbf{t a}_{\mathbf{5}}$ & $\mathbf{L R}$ & $\mathbf{B V}$ & $\mathbf{S V}$ & $\mathbf{B R}$ \\
\hline $\mathbf{P}_{\mathbf{1}}$ & 851 & 898 & 733 & 406 & 281 & 191 & 99 & 0.82 & 2.5 & 2.4 & 2.4 \\
$\mathbf{P}_{\mathbf{2}}$ & 826 & 756 & 446 & 218 & 155 & 102 & 88 & 0.59 & 3.6 & 3.6 & 2.7 \\
$\mathbf{P}_{\mathbf{3}}$ & 835 & 819 & 522 & 252 & 170 & 113 & 94 & 0.64 & 3.5 & 3.2 & 4.4 \\
\hline
\end{tabular}



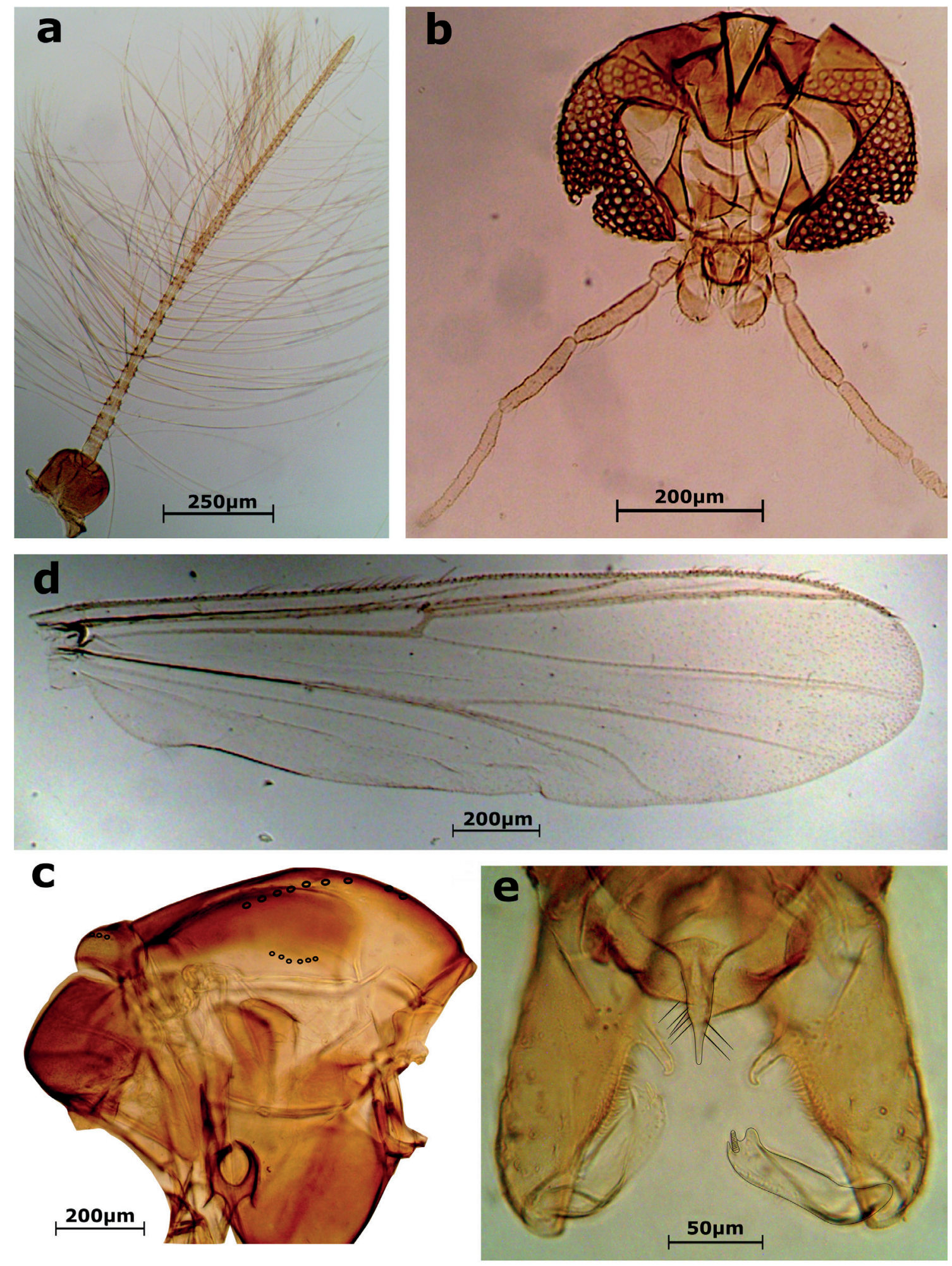

Figure 1. Parametriocnemus hamatus (Johannsen) male. a) antenna, b) head, c) thorax lateral view, d) wing, e) hypopygium. 
larged, broadly projecting above the inner margin of Gs (Sæther 1969, fig. 65).

P. vespertinus Sæther

3b. AnP short, reaching only as far as IVo; CD either inconspicuous or present as small preapical to oth.

4a. IVo with a broad basal attachment about half the length of Gc. AnP with weak lateral setae (Sæther 1969, fig. 63; Sublette 1967, fig. 33)......

\section{P. lundbeckii (Johannsen)*}

4b. IVo with narrow basal attachment about quarter length of Gc. AnP with bristle-like setae..........5

5a. Gs angular distally with dorsal ridge ending in small sharply pointed CD (Sæther 1969, fig. 58)... P. eoclivus Sather

5b. Gs somewhat rounded distally with weak dorsal margin merging with poorly defined CD (Gowin and Thienemann 1942, fig. 2)

\section{P. boreoalpinus Gowin and Thienemann}

*Will also key to Parametriocnemus stylatus (Spärck, 1923), a Palearctic species. Parametriocnemus lundbeckii and P. stylatus closely resemble each other. The two species can partially be separated based on the characters of gonostyle. The gonostyle of $P$. stylatus is much narrower and tubeshape. It also lacks the prominent crista dorsalis present in most variations of $P$. lundbeckii. Sæther (1969) suggested that the synonymy of both species cannot be excluded. However, the two species can be separated based on partial COI DNA sequences (DNA barcodes).

\section{Rheocricotopus (Rheocricotopus) reduncusoides sp. $n$. \\ http://zoobank.org/urn:lsid:zoobank. org:act:BD1AEE59-F9A2-4EBB-9BB6- 791096FFB959}

\section{(Figs 2a-c \& 3a-c)}

Material examined. Holotype: $1 \hat{\jmath}$ slide-mounted in Canada Balsam, Bathurst Island, Nunavut, $75^{\circ}$ $43^{\prime}$ N, $98^{\circ} 25^{\prime}$ W, 10 July 1969, Coll. H.V. Danks, CH 1214 (CNC). Paratypes: 4 ổ slide-mounted in Canada Balsam, Bathurst Island, Nunavut, $75^{\circ}$ 43’ N, $98^{\circ} 25^{\prime}$ W, 10 July 1969, Coll. H.V. Danks,
CH 1214 (CNC). Rheocricotopus (Rheocricotopus) reduncus Sæther and Schnell, 1988: 3 Paratypes, $\widehat{\partial} \widehat{\jmath}$, Jostedøla River at Inlet to small lake, Luster, Sogn and Fjordane, Norway, 23/7' 86, A. Fjellheim and A. Schnell (ZMB NO. 116).

Etymology: From Latin, reduncus meaning curved or hooked backward which refers to the shape of caudomedian projection of superior volsella, and the epithet of the most closely related species, and New Latin oides, referring to the likeness of form.

Diagnostic characters. HP small to indistinct. SVo with long caudomedian projections evenly curved, medially projected and opposing each other, apex slightly pointed. Sternapodme broad horizontal band. IVo simple, small, blunt, slightly dilated at the apex. $\mathrm{AR}=0.75 . \mathrm{BR}_{1-3}=1.4,1.2,1.4$. AnP $67 \mu \mathrm{m}$ long with 13-19 setae. Gs with slight bent distally, $\mathrm{CD}$ developed, long and low. $\mathrm{HR}=1.6$.

Male $(\mathrm{n}=5)$. Total length $=3.1 \mathrm{~mm}$

Coloration of slide-mounted specimen: Head and thorax dark brown, abdomen golden-brown, halter light brown with dorsolaterals darker, and wing yellowish brown.

Head. As in Fig. 2a. Antenna (Fig. 2b) with 13 flagellomeres, ultimate flagellomere $332 \mu \mathrm{m}$ long, $\mathrm{AR}=0.72-0.79(0.75)$. Tentorium $\mathrm{L}=152 \mu \mathrm{m}$. 4 Coronal setae. Temporal setae consisting of: 3 postorbitals, 1 inner verticals, 2 outer verticals present. Clypeus wider than long $(\mathrm{L}=119 \mu \mathrm{m}, \mathrm{W}=$ $132 \mu \mathrm{m})$, bearing six setae. Palpomere $\mathrm{p}_{1-5}$ lengths $(\mu \mathrm{m}): 51,55,79,88,144$; sensilla clavata difficult to see on $3^{\text {rd }}$ palpomere.

Thorax. As in Fig. 2c. 7-8 antepronotals. 4-5 (4) acrostichals close to antepronotum ( $\mathrm{L}=11 \mu \mathrm{m})$. Dorsocentrals 7-9, uniserial $(\mathrm{Ls}=57-69 \mu \mathrm{m})$. Prealars 2-3.

Wing. As in Fig. 3a. Wing with fine punctation. L $=2 \mathrm{~mm}, \mathrm{~W}=0.5 \mathrm{~mm}$. Squama with 4-5 setae, brachiulum with 1 seta, $\mathrm{R}$ with 5-6 setae, $\mathrm{R}_{1}$ bare, $\mathrm{R}_{4+5}$ with 2 setae. Costa slightly extends past $\mathrm{R}_{4+5}$ $(\mathrm{L}=30 \mu \mathrm{m})$.

Legs. Fore legs with tibial spur $41 \mu \mathrm{m}$ long, mid tibial spurs 25 and $16 \mu$ long, hind tibial spurs 44 and $23 \mu$ long, comb with $15-17$ setae. Pseudospurs

Table 2. Male leg lengths $(\mu \mathrm{m})$ and proportions of Rheocricotopus $(R$.) reduncusoides $\mathrm{sp} . \mathrm{n}$.

\begin{tabular}{lccccccccccc}
\hline & $\mathbf{f e}$ & $\mathbf{t i}$ & $\mathbf{t a}_{\mathbf{1}}$ & $\mathbf{t a}_{\mathbf{2}}$ & $\mathbf{t a}_{\mathbf{3}}$ & $\mathbf{t a}_{\mathbf{4}}$ & $\mathbf{t a}_{\mathbf{5}}$ & $\mathbf{L R}$ & $\mathbf{B V}$ & $\mathbf{S V}$ & $\mathbf{B R}$ \\
\hline $\mathbf{P}_{\mathbf{1}}$ & 671 & 738 & 459 & 304 & 227 & 128 & 108 & 0.6 & 2.4 & 3.1 & 1.4 \\
$\mathbf{P}_{\mathbf{2}}$ & 702 & 666 & 320 & 189 & 145 & 82 & 94 & 0.5 & 3.3 & 4.3 & 1.2 \\
$\mathbf{P}_{\mathbf{3}}$ & 690 & 773 & 393 & 221 & 182 & 92 & 92 & 0.5 & 3.2 & 3.7 & 1.4 \\
\hline
\end{tabular}


are absent on $t_{1}$ and $t_{2}$ of mid and hind legs. Mid and hind femur with keel. Pulvilli well-developed, almost half as long as the claws. Lengths and proportions of legs in Table 2.

Hypopygium. As in Fig. 3b. Laterosternite IX with 6-7 setae $(\mathrm{L}=25 \mu \mathrm{m})$. Phallapodme (59-66) 64 $\mu \mathrm{m}$ long; sternapodeme (90-105) $99 \mu \mathrm{m}$ long. Anal point mostly hyaline, triangular with 13-19 setae, (56-89) $67 \mu \mathrm{m}$ long. Superior volsella (Fig. $3 \mathrm{~b}-\mathrm{c})$ with caudomedian projections long, finger-

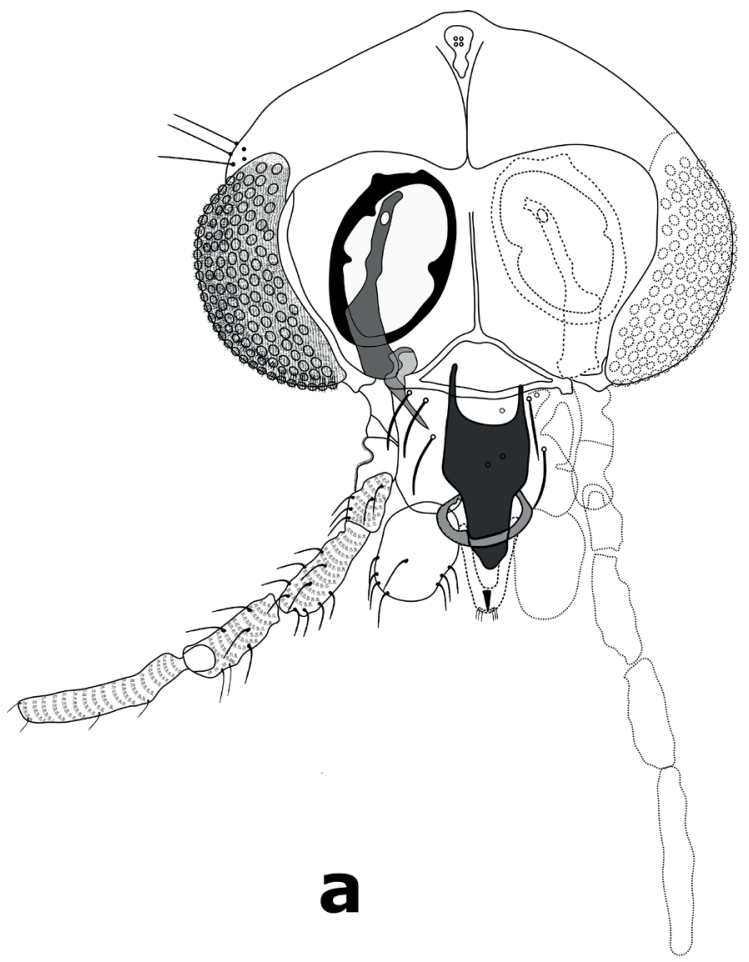

like, curved evenly before meeting medially, $\mathrm{L}=$ $84 \mu \mathrm{m}$. Inferior volsella simple triangular, lobe with blunt tip and slightly dilated at apex, $\mathrm{L}=19$ $\mu \mathrm{m}$. Gonocoxite $278 \mu \mathrm{m}$ long. Gonostyle curved with slight bent distally (Fig. 3b), L $=171 \mu \mathrm{m}$. Crista dorsalis long and low, megaseta $\mathrm{L}=17 \mu \mathrm{m}$. $\mathrm{HR}=1.6, \mathrm{HV}=1.8$.

Remarks. This species is closely related to the Rheocricotopus (Rheocricotopus) reduncus. Combination of lower AR, lower BR, higher number of

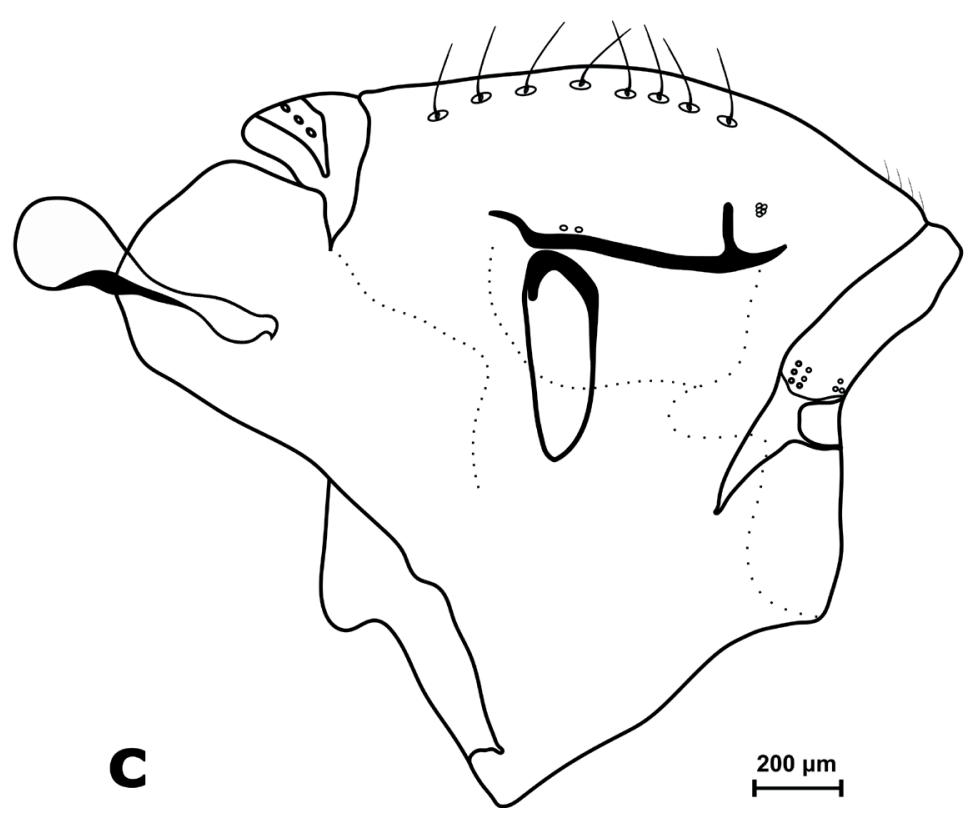

Figure 2. Rheocricotopus $(R$.) reduncusoides sp. n. male. a) head, b) antenna, c) thorax lateral view. 

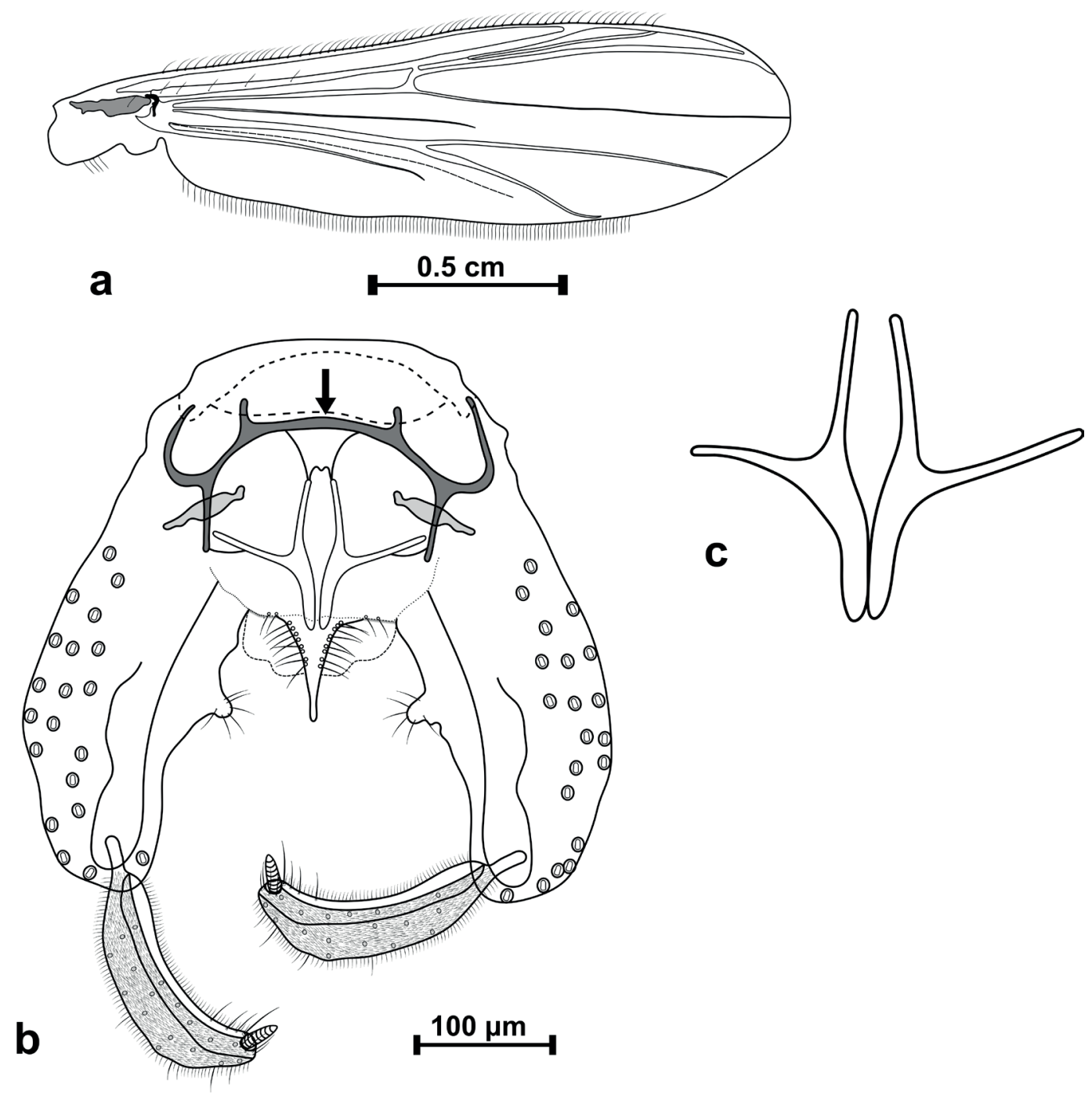

Figure 3. Rheocricotopus $(R$.) reduncusoides sp. n. male. a) wing, b) hypopygium, arrow indicates the sternapodeme, c) superior volsella caudomedian projection.
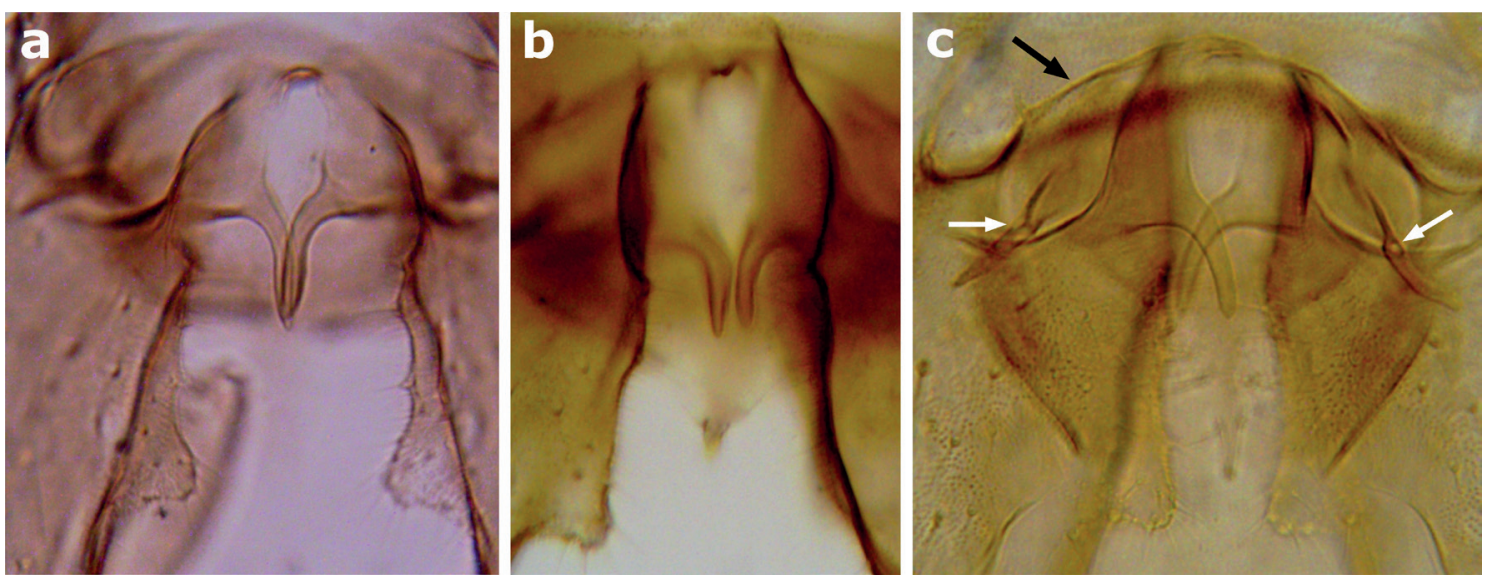

Figure 4. Rheocricotopus $(R$.) reduncus Sæther and Schnell, male paratypes from Norway. a) caudomedian projection and inferior volsella, b) variation of the caudomedian projection and inferior volsella, c) sternapodeme (black arrow) and phallapodeme (white arrows). 
Table 3. Comparison of some members of Rheocricotopus (R.) effusus group's adult male. Modified from Sæther and Schnell (1988). Ac = Acrostichals, AnP = Anal Point; CD = Crista Dorsalis, Gs = Gonostyle, HP = Humeral Pit; IVo = Inferior Volsella; SVo $=$ Superior Volsella, $\mathrm{L}=$ Lengths in $\mu \mathrm{m}$.

\begin{tabular}{lcccccc}
\hline \multicolumn{1}{c}{ Species } & AR & No. Dc & No. Ac & HP & LR $_{\mathbf{1}}$ & AnP L \\
\hline $\boldsymbol{R}$. unidentatus & $1.10-1.36$ & $18-22$ & $30-36$ & Large ellipsoid & 0.71 & $41-60$ \\
$\boldsymbol{R}$. effusus & $0.99-1.33$ & $9-16$ & $18-26$ & Large ellipsoid & $0.70-0.74$ & $<75$ \\
$\boldsymbol{R}$. effusoides & $1.39-1.69$ & $12-16$ & $14-21$ & Large ellipsoid & $0.64-0.67$ & $75-98$ \\
$\boldsymbol{R}$. pauciseta & $0.6-0.83$ & $5-7$ & $12-17$ & small & $0.62-0.74$ & $36-40$ \\
$\boldsymbol{R}$. reduncus & $0.83-1.17$ & $7-12$ & $3-9$ & small & $0.62-0.67$ & 38 \\
$\boldsymbol{R}$. reduncusoides & $0.72-0.79$ & $7-9$ & $4-5$ & small & $0.60-0.66$ & $56-89$ \\
\hline
\end{tabular}

\begin{tabular}{|c|c|c|c|c|c|c|}
\hline & AnP setae & HR & $\begin{array}{c}\text { Stern- } \\
\text { apodeme }\end{array}$ & SVo & IVo & Gs \\
\hline R. unidentatus & $8-12$ & $2.42-2.50$ & $\begin{array}{l}\text { Arched } \\
\text { upward }\end{array}$ & $\begin{array}{l}\text { Tooth-like } \\
\text { caudomedian } \\
\text { projection }\end{array}$ & $\begin{array}{c}\text { Large, } \\
\text { simple with } \\
\text { pointed apex }\end{array}$ & $\begin{array}{l}\text { Curved } \\
\text { evenly }\end{array}$ \\
\hline R. effusus & $5-13$ & - & $\begin{array}{l}\text { Arched } \\
\text { upward }\end{array}$ & $\begin{array}{l}\text { Tooth-like } \\
\text { caudomedian } \\
\text { projection }\end{array}$ & $\begin{array}{c}\text { Large, } \\
\text { simple with } \\
\text { pointed apex }\end{array}$ & $\begin{array}{c}\text { Curved } \\
\text { evenly with } \\
\text { low and } \\
\text { long CD }\end{array}$ \\
\hline R. effusoides & $15-12$ & $1.92-2.07$ & $\begin{array}{l}\text { Arched } \\
\text { upward }\end{array}$ & $\begin{array}{l}\text { Tooth-like } \\
\text { caudomedian } \\
\text { projection }\end{array}$ & $\begin{array}{c}\text { Large, } \\
\text { simple with } \\
\text { slightly } \\
\text { hooked apex }\end{array}$ & $\begin{array}{c}\text { Curved } \\
\text { evenly with } \\
\text { low and } \\
\text { long CD }\end{array}$ \\
\hline R. pauciseta & $6-8$ & $2.61-2.69$ & $\begin{array}{l}\text { Arched } \\
\text { upward }\end{array}$ & Triangular & $\begin{array}{c}\text { Divided into } \\
2 \text { small lobes } \\
\text { with dorsal } \\
\text { one naked }\end{array}$ & $\begin{array}{c}\text { Plump, } \\
\text { broad } \\
\text { at apex, } \\
\text { without CD }\end{array}$ \\
\hline R. reduncus & $6-11$ & $1.82-2.00$ & $\begin{array}{l}\text { Narrow } \\
\text { and } \\
\text { arched } \\
\text { upward }\end{array}$ & $\begin{array}{l}\text { Mainly bent, } \\
\text { short digitiform } \\
\text { caudomedian } \\
\text { projection, } \\
\text { caudally } \\
\text { appearing } \\
\text { closely parallel } \\
\text { to one another } \\
\text { or overlapping } \\
\text { each other }\end{array}$ & $\begin{array}{c}\text { Small, } \\
\text { simple } \\
\text { with blunt } \\
\text { tip. Evenly } \\
\text { tapered at } \\
\text { the apex }\end{array}$ & $\begin{array}{l}\text { Long, } \\
\text { curved } \\
\text { evenly with } \\
\text { very low } \\
\text { CD that } \\
\text { may appear } \\
\text { absent }\end{array}$ \\
\hline R. reduncusoides & $12-19$ & $1.50-1.80$ & $\begin{array}{c}\text { Broad } \\
\text { horizontal } \\
\text { band }\end{array}$ & $\begin{array}{c}\text { Evenly curved, } \\
\text { long digitiform } \\
\text { caudomedian } \\
\text { projections } \\
\text { medially } \\
\text { projected and } \\
\text { opposing each } \\
\text { other }\end{array}$ & $\begin{array}{c}\text { Small, } \\
\text { simple, } \\
\text { slightly } \\
\text { dilated at the } \\
\text { apex }\end{array}$ & $\begin{array}{c}\text { Long, } \\
\text { slightly bent } \\
\text { distally, CD } \\
\text { developed, } \\
\text { long and } \\
\text { low }\end{array}$ \\
\hline
\end{tabular}


setae on AnP, longer AnP, a more evenly curved caudomedian projection of SVo (Figs 3b-c; compared to mainly bent in $R$. reduncus Fig. $4 \mathrm{a}-\mathrm{b}$ ), apically dilated IVo, broad horizontal sternapodeme (Fig. 3b; compared to narrow arched in $R$. reduncus, Fig. 4c), lower HR and HV separates the two species.

Based on the form of SVo this species belongs to the effusus group. Given the similarity of $R$. reduncus, $R$. reduncuiodes with other species within the effusus group a re-evaluation of the distinguishing characters is required to separate the species. In the effusus group the anal point length and thoracic chaetotaxy characters may not be sufficient to separate the species in this group. Sæther and Schnell (1988) provided a somewhat better alternative for separating species in this group by listing the main comparative characters in a table. Following their example, we modified and corrected some of these characters and added few more (Table 3 ).

A notable change to the characters given by Sæther and Schnell (1988) is the AR range of $R$. reduncus. The Norwegian specimens of $R$. reduncus described by Sæther and Schnell (1988) have AR 0.83-0.90 while Makarchenko and Makarchenko (2005) described the species from Far Eastern Russia with AR range of 1.16-1.17. This somewhat changes the state of characters given by Sæther (1985) and discussed by Sæther and Schnell (1988). If we are to consider Makarchenko and Makarchenko (2005) description of $R$. reduncus then the trend 8 of Sæther's (1985) classification of the genus, describing a male AR of 0.6-0.8, does not longer hold for this species. Consequently, the characteristic of AR should no longer be considered apomorphic for $R$. reduncus. For $1^{\text {st }}$ of trend 7 in Sæther's (1985) both $R$. reducncus and $R$. reduncusoides are synapomorphous (digitiform caudomedian projection) and symplesiomorphous for second (with small humeral pit). The broad horizontal sternapodeme of $R$. reduncusoides is autapomorphic for this species.

Key to the known Nearctic adult male Rheocricotopus Thienemann and Harnisch (Modified from Sather, 1985)

Abbreviations: $\mathrm{AnP}=$ Anal Point; $\mathrm{CD}=$ Crista Dorsalis; Gc = Gonocoxite; Gs = Gonostyle; HP $=$ Humeral Pit; IVo = Inferior Volsella; SVo $=\mathrm{Su}-$ perior Volsella.

1a. Gs either with prominent preapical triangular CD or it's bent distally, and CD is more apical. SVo broadly rounded, never with projection. Subgenus Psilocricotopus. 1b. Gs either without apparent CD or its long, low and rounded distally. SVo with or without caudomedian projection. Subgenus Rheocricotopus.....6

2a. HP of thorax small and indistinct. (Sæther 1985, fig. 2B). $\mathrm{AR}<0.7$

R. (P.) conflusirus Sæther

2b. HP of thorax large and distinct. AR $>0.7 \ldots \ldots . .3$

3a. HP very large, rectangular (Sæther 1985, fig. 11B). Gs is not bent upwards distally (Sæther 1985, fig. 11D)..........R. (P.) glabricollis (Meigen)

3b. HP moderately large, ovoid or circular, if very large and rectangular then Gs is bent upwards distally. ...4

4a. Gs with CD tooth-like located apically next to the megaseta (Lehmann 1969, fig. 1; Pinder 1978, fig. 38c). R. (P.) chalybeatus (Edwards)

4b. Gs with triangular preapical CD distinctly separated from megaseta............................................5

5a. Gs strongly bent distally (Sæther 1969, fig. 44) Costa not produced.

..R. (P.) robacki (Beck and Beck)

5b. Gs not strongly bent (Sæther 1985, fig. 4D). Costa moderately produced (Sæther, 1985, fig. 4C)

R. (P.) chapmani (Edwards)

6a. SVo with or without caudomedian projection. .7

6b. SVo broadly rounded without caudomedian projection

7a. SVo triangular without distinct caudomedian projection (Sæther 1971, fig. 8D). IVo distally divided into two lobes. (Sæther 1969, fig.47).

R. (R.) pauciseta Sæther

7b. SVo with distinct caudomedian projection. IVo simple. . .8

8a. HP small (Fig. 2c). SVo with long finger-like caudomedian projections that meet medially (Fig. $3 b-c)$.

$\boldsymbol{R}$. (R.) reduncusoides sp. n.

8b. HP large. SVo conical with short tapered caudomedian projections (Sæther 1985, figs. 18b, d \& e; Sæther and Schnell 1988, figs. 3b \& d)

R. (R.) effusoides (Walker), R. (R.) effusus Sæther, $\boldsymbol{R}$. (R.) unidentatus Sæther and Schnell ${ }^{\dagger}$

9a. CD weak to absent. $A R=0.66-0.97$. Costa with definite extension $\geq 15 \mu \mathrm{m}$ 10

9b. CD present as long distally rounded ridge (Sæther 1985, fig.16C). AR $\geq 1.0$. Costa extension barely indicated $<15 \mu \mathrm{m}$ (Sæther 1985, fig.16B). R. (R.) amplicristatus Sather 
10a. Gc with inner proximal margin bulges slightly before it meets the IVo that strongly projects medially (Sæther 1969, fig. 43; Makarchenko and Makarchenko 2005, fig. 16). Costal extension $\sim 30$ $\mu \mathrm{m}$. R. (R.) eminellobus Sæther*

10b. Gc with inner proximal margin continuing straight where it meets the IVo which ends in a small posteriorly directed lobe. (Sæther 1985, fig.15C; Caldwell 1984, fig. 2). Costal extension 15-30 $\mu \mathrm{m}$ R. (R.) tuberculatus Caldwell*

*Will also key to $R$. reduncus Sæther and Schnell, a Palearctic species. See diagnosis and remarks under $R$. reduncusoides, and Table 3 to separate the two species.

$\dagger$ Theses three species in the effusus group are difficult to separate. See Table 3 for combination of characters, distinguishing the species in the effusus group.

*Adult male of $R$. eminellobus and $R$. tuberculatus are very similar. Key above can partially separate the two species. Female, pupa and larva of two species are quite distinguishable.

\section{Acknowledgements}

Our sincere thanks to Dr. Hugh Danks who provided detailed information about his collection from Bathurst Island. Many thanks to staff and researchers at the Diptera section of the Canadian National Collection of Insects, Arachnids and Nematodes, Ottawa especially Dr. Jeff Cummings, Dr. Scott Brooks and Dr. Bradley Sinclair for facilitating this study. Many thanks to Dr. Trond Andersen of Department of Natural History, University $\mathrm{Mu}-$ seum of Bergen for providing the type specimens for this study. Finally, our sincere thanks to two anonymous reviewers who provided a very comprehensive information and point by point corrections which greatly improved the content and the quality of our study.

\section{References}

Albu, P. 1968. Chironomide din Carpatii românesti (III). - Studii şi Cercetări de Biologie, Série de Zoologie. Bot. 20(5): 455-465.

Ashe, P. and O'Connor, J.P. 2012. A world catalogue of Chironomidae (Diptera) Part 2 Orthocladiinae, Sections $A$ and B. Irish Biogeographical Society and National Museum of Ireland, Dublin, Ireland, 968 p.

Beck, W.M. and Beck, E.C. 1964. New Chironomidae from Florida (Diptera). - The Florida Entomologist 47: 201-207.

Bolton, M.J. 1992. Chironomidae (Diptera) of
Cedar Bog, Champaign County, Ohio. - Ohio Journal of Science 92(5): 147-152.

Caldwell, B.A. 1984. Two new species and records of other Chironomids from Georgia (Diptera: Chironomidae) with some observation on ecology. - Georgia Journal of Science 42: 81-96.

Cranston, P.S. 1982. A key to the larvae of the British Orthocladiinae (Chironomidae). -Scientific Publication Freshwater Biological Association 45: 1-152.

Danks, H.V. 1971. Overwintering of some north temperate and arctic Chironomidae. II. Chironomid biology. -Canadian Entomologist 103(12): 1875-1910. DOI: https://doi. org/10.4039/Ent103589-4

Danks, H.V. 1980. Arthropods of Polar Bear Pass, Bathurst Island, arctic Canada. Syllogeus. 68 pp.

Danks, H.V. 1981. Arctic arthropods. A review of systematics and ecology with reference to the North American fauna. Entomological Society of Canada, Ottawa. 608 pp.

Danks, H.V. and Byers, J.R., 1972. Insects and arachnids of Bathurst Island, Canadian Arctic Archipelago. - Canadian Entomologist 104(1): 81-88. DOI: https://doi.org/10.4039/ Ent10481-1

Danks, H.V. and Oliver, D.R. 1972a. Seasonal emergence of some high arctic Chironomidae (Diptera). - Canadian Entomologist 104(5): 661-686. DOI: https://doi.org/10.4039/ Ent105837-6

Danks, H.V. and Oliver, D.R. 1972b. Diel periodicities of emergence of some high arctic Chironomidae (Diptera). - Canadian Entomologist 104(6): 903-916. DOI: https://doi. org/10.4039/Ent104903-6

Epler, J.H. 2001. Identification manual for the larval Chironomidae (Diptera) of North and South Carolina. A guide to the taxonomy of the midges of the southeastern United States including Florida. Special Publication SJ2001SP13. North Carolina Department of Environment and Natural Resources Division of Water Quality and St. Johns River Water Management District, Palatka, FL, 530p.

Gowin, F. and Thienemann, A. 1942. Zwei neue Orthocladiinen-Arten aus Lunz (Niederdonau). Chironomiden aus dem Lunzer Seengebiet VII. - Zoologischer Anzeiger 140(7/8): 101-109. 
Hudson, P.L. Lenat, D. R., Caldwell, B.A. and Smith D., 1990. Chironomidae of the southeastern United States: a checklist of species and notes on biology, distribution, and habitat. US Fish and Wildlife Publications 53 p.

Johannsen, O.A. 1934. New species of North American Ceratopogonidae and Chironomidae. - Journal of the New York Entomological Society 42(3): 343-352.

Kownacka, M. and Kownacki, A. 1967. Parametriocnemus boreoalpinus Gowin et Thienemann 1942 (Tendipedidae, Diptera) nowy gatunek dla Tatr (Parametriocnemus borealpinus Gowin et Thienemann 1942 (Tendipedidae, Diptera) new species for the Tatra Mts). - Acta Hydrobiologica 9: 187-191.

Krasheninnikov, A.B., Orel, O.V. and Loskutova, O.A. 2015. New data on chironomid fauna (Diptera, Chironomidae) of the Pay-Khoy ridge and the Polar Urals, Russia. - Euroasian Entomological Journal. 14: 416-428. [In Russian]

Langton, P.H. 1991. A key to pupal exuviae of West Palaearctic Chironomidae. Private publication. Printed by Graytones, UK. 386 p.

Lehmann, J. 1969. Die europäischen Arten der Gattung Rheocricotopus Thien. und Harn. und drei neue Artvertreter dieser Gattung aus der Orientalis (Diptera, Chironomidae). - Archiv für Hydrobiologie 66(3): 348-381.

Li, X., Lin, X. and Wang, X. 2013. New species and records of Parametriocnemus Goetghebuer from China (Diptera, Chironomidae). ZooKeys. 320: 51-62.

Liu, W., Lin, X. and Wang, X. 2014a. A review of Rheocricotopus (Psilocricotopus) chalybeatus species group from China, with description of three new species (Diptera, Chironomidae). ZooKeys 388: 17-34.

Liu, W, Song, C. and Wang, X. 2014b. Review of the subgenus Rheocricotopus (s. str.) Brundin, 1956 from China (Diptera, Chironomidae). Pan-Pacific Entomologist 90: 100-106.

Makarchenko, E.A. and Makarchenko, M.A. 2005. Chironomidae of the genus Rheocricotopus Thienemann et Harnisch, 1932 (Diptera, Chironomidae, Orthocladiinae) of the Russian Far East. - Eurasian Entomological Journal 4(2): 126-134.

McShaffrey, D. and Olive, J.H. 1985. Ecology and Distibution of Chironomid Larvae from Car- roll County, Ohio (Diptera: Chironomidae). The Ohio Journal of Science 85(4): 190-198.

Moubayed-Breil, J. 2016. Rheocricotopus (Psilocricotopus) meridionalis sp. $\mathrm{n}$. and $R$. (Psc.) thomasi sp. n., two crenophilous species inhabiting cold helocrenes and streams in the Mediterranean Region [Diptera, Chironomidae, Orthocladiinae]. - Ephemera 16 (2): 71-91.

Namayandeh, A., Bilyj, B., Beresford, D.V., Somers, K.M. and Dillon P.J. 2012. Chironomidae (Diptera) larvae of Precambrian Shield headwater streams, Canada. - Zootaxa 3324: 1-165.

Namayandeh, A., Heard, K.S., Luiker, E.A. and Culp, J.M. 2016. Chironomidae (Insecta: Diptera) from the eastern Canadian Arctic and subarctic with descriptions of new life stages, a possible new genus, and new geographical records. - Journal of Entomological and Acarological Research 48(2): 53-200. DOI: https:// doi.org/10.4081/jear.2016.5847

Namayandeh, A. and Culp, J.M. 2016. Chironomidae larvae from the lower Athabasca River, $\mathrm{AB}$, Canada and its tributaries including macroscopic subfamily and tribe keys, indices for environmental tolerance and trait-based information for biomonitoring. - Journal of Entomological and Acarological Research 48(2): 201-300. DOI: https://doi.org/10.4081/ jear.2016.6075

Namayandeh, A. 2016. Re-description of the female of Meropelopia flavifrons and Chaetocladius perennis, and larvae of Chaetocladius perennis (Diptera: Chironomidae), with new geographical records from Atlantic Canada. Journal of the Acadian Entomological Society 12: 7-21.

Oliver, D.R. and Danks. H.V. 1972. Sex ratios of some high arctic Chironomidae (Diptera). - $\mathrm{Ca}$ nadian Entomologist 104(9): 1413-1417. DOI: https://doi.org/10.4039/Ent1041413-9

Pinder, L.C.V. 1978. A key to adult males of the British Chironomidae (Diptera), Vol. 1, The key; Vol. 2, Illustrations of the Hypopygia. Freshwater Biological Association Scientific Publication 37: 1-169.

Ratnasingham, S. and Hebert, P.D. 2007. BOLD: The Barcode of Life Data System (http://www. barcodinglife. org). - Molecular Ecology Resources 7(3): 355-364. DOI: http://dx.doi. org/10.1111/j.1471-8286.2007.01678.x.

Sæther, O.A. and Schnell, O.A. 1988. Two new species of the Rheocricotopus (R.) effusus 
group (Diptera, Chironomidae). - Spixiana Supplement 14: 65-74.

Sæther, O. A. and Spies. M. 2013. Fauna Europaea: Chironomidae. Fauna Europaea: Diptera Nematocera. Fauna Europaea version 2.2.

Sæther, O.A. 1969. Some Nearctic Podonominae, Diamesinae, and Orthocladiinae (Diptera: Chironomidae). - Bulletin of Fisheries Research Board of Canada 170: 1-154.

Sæther, O.A. 1971. Notes on general morphology and terminology of the Chironomidae (Diptera). - The Canadian Entomologist 103: 1237-1260. DOI: https://doi.org/10.4039/ Ent1031237-9

Sæther, O.A. 1980. Glossary of chironomid morphology terminology (Diptera: Chironomidae). - Entomologica Scandinavica Supplement 14: $1-51$.

Sæther, O.A. 1985. A review of the genus Rheocricotopus Thienemann and Harnisch, 1932, with the description of three new species (Diptera, Chironomidae). - Spixiana Supplement 11: 59108.
Simpson, K.W. and Bode, R.W. 1980. Common larvae of Chironomidae (Diptera) from New York State streams and rivers with particular reference to the fauna of artificial substrates. New York State Museum Bulletin 439: 1-105.

Sublette, J.E. 1967. Type specimens of Chironomidae (Diptera) in the Cornell University collection. - Journal of the Kansas Entomological Society 477-564.

Sublette, J.E. 1966. Type specimens of Chironomidae (Diptera) in the U.S. National Museum. - Journal of the Kansas Entomological Society 39(4): 580-667.

Yamamoto, M. and Yamamoto, N. 2017. A new species of the genus Rheocricotopus Brundin from Japan (Diptera: Chironomidae: Orthocladiinae). - Japanese Journal of Systematic Entomology 23: 75-79.

Article submitted 10. May 2018, accepted by Torbjørn Ekrem 18. December 2018, published 27. December 2018. 